\title{
PRÁTICA CLÍNICA EM SAÚDE MENTAL NO COTIDIANO DO CENTRO DE ATENÇÃO PSICOSSOCIAL
}

Antonio Germane Alves Pintoํㅜ Maria Salete Bessa Jorge²

\begin{abstract}
RESUMO: Objetiva-se com o presente trabalho analisar a prática clínica operada pelos trabalhadores de saúde mental no cotidiano do Centro de Atenção Psicossocial. Trata-se de um estudo crítico-analítico com abordagem qualitativa realizado em Fortaleza-CE, numa unidade do Centro de Atenção Psicossocial, junto a 14 trabalhadores de saúde mental. Os resultados expressam o esforço pactuado em efetivar abordagens voltadas para a subjetividade humana em todos os momentos da assistência no Centro de Atenção Psicossocial. O grupo terapêutico permeia as iniciativas de intervir, assistir, cuidar, e assim, constitui uma estratégia para o desenvolvimento do projeto terapêutico. Desta forma, o campo da clínica psicossocial é fortalecido pela transversalidade de saberes e a diversidade das práticas.

PALAVRAS-CHAVE: Saúde mental; Guia de prática clínica; Serviços de saúde mental.

\section{CLINICAL PRACTICE IN MENTAL HEALTH IN THE DAILY WORK OF PSYCHOSOCIAL ATTENTION CENTER}

\begin{abstract}
The objective of the present work is to analyze the clinical practice operated by mental health workers in the daily work of a Psychosocial Attention Center (CAPS). It is a critical-analytical study with a qualitative approach developed in Fortaleza-CE, in an unit of CAPS, with 14 mental health workers. The results express the effort in executing approaches towards the human subjectivity in all attendance moments in CAPS. The therapeutic group permeates the initiatives of intervening, of attending, of caring, and then it constitutes a strategy for the development of the therapeutic project. In this way, the clinic psychosocial field is strengthened by the transversality of knowledges and the diversity of practices. KEYWORDS: Mental health; Practice guidelines as topic; Mental health services.
\end{abstract}

\section{PRÁCTICA CLÍNICA EN SALUD MENTAL EN EL COTIDIANO DEL CENTRO DE ATENCIÓN PSICOSOCIAL}

RESUMEN: El objetivo del presente trabajo fue analizar la práctica clínica hecha por los trabajadores de salud mental en el cotidiano del Centro de Atención Psicosocial. Se trata de un estudio crítico-analítico con abordaje cualitativo realizado en Fortaleza-CE, en una unidad del Centro de Atención Psicosocial, con 14 trabajadores de salud mental. Los resultados expresan el esfuerzo pactado en efectuar abordajes volcados para la subjetividad humana en todos los momentos de la asistencia en el Centro de Atención Psicosocial. El grupo terapéutico permea las iniciativas de intervenir, asistir, cuidar, y así, constituye una estrategia para el desarrollo del proyecto terapéutico. De esta manera, el campo de la clínica psicosocial se fortalece por la transversalidad de conocimientos y la diversidad de las prácticas.

PALABRAS CLAVE: Salud Mental; Guías de la práctica clínica como asunto; Servicios de salud mental.

\footnotetext{
${ }^{1}$ Mestre em Cuidados Clínicos em Saúde. Universidade Estadual do Ceará-UECE. Docente do Departamento de Enfermagem da Universidade Regional do Cariri-URCA.

2Doutora em Enfermagem. Universidade de São Paulo-USP. Professora Titular-UECE. Pesquisadora 1C CNPq. Docente e coordenadora do Curso de Mestrado Acadêmico em Saúde Pública-UECE e do Curso de Doutorado em Saúde Coletiva-Associação Ampla de IES UECE-UFC. Docente do Curso de Mestrado Acadêmico Cuidados Clínicos em Saúde-UECE.
}

Autor correspondente:

Antonio Germane Alves Pinto

Rua Antonio Alves de Morais Jr, 10 - 63107-020 - Crato-CE

Recebido: 28/09/08

E-mail: germanepinto@hotmail.com

Aprovado: 18/05/09 


\section{INTRODUÇÃO}

No campo da saúde mental, o paradigma psiquiátrico e a reforma da assistência culminaram com o processo de desinstitucionalização. Dessa forma, vem sendo possível superar o fechamento dos hospícios e/ou o abandono das pessoas nas ruas ou com suas famílias, com a possibilidade de efetivar o acompanhamento do sujeito em sua existência e em relação às suas condições de vida ${ }^{(1)}$.

Historicamente, fica evidente a necessidade do espaço do cuidado conformado no Centro de Atenção Psicossocial-CAPS como estratégia e mecanismo agenciador das ações de saúde mental no Sistema Único de Saúde-SUS. O cotidiano deste dispositivo apresenta uma diversidade de atividades e procedimentos voltados para o restabelecimento da condição humana saudável de cada usuário atendido.

A prática clínica está inserida na dialética da relação exercida entre os trabalhadores de saúde e os usuários no paradigma da transformação do modo de fazer saúde. A ressignificação do cuidado e de seus dispositivos perpassa pela consciência de cada sujeito em sua contemporaneidade absoluta ou relativa ${ }^{(2)}$. Desta forma, a assistência em saúde mental procura construir um novo modelo terapêutico, baseando-se na ampliação da clínica e no enfoque do sujeito-usuário. O cuidado se constitui integral a partir do acolhimento no território em que emerge a formação do vínculo e a coresponsabilização pela busca da resolubilidade nas necessidades de saúde. Tais demandas, são recompostas na escuta que evidencia os problemas reais e a criação de possibilidades no convívio com o sofrimento psíquico e suas relações sócio-culturais ${ }^{(3-5)}$.

A fragmentação do cuidado e a desresponsabilização pelo usuário são constituídas pela condição estática e departamentalizada do processo condutor da terapêutica e constituem um empecilho ao desenvolvimento de condutas emancipatórias. A clínica ampliada torna-se requisito para a prática, em que o diálogo deve dar-se na própria rede de cuidados de saúde mental, no sentido de favorecer a autonomia do usuário ${ }^{(3-5)}$.

A intensificação do encontro entre os sujeitos na prática clínica, ou seja, o trabalhador de saúde e o usuário, possibilita a formação de vinculação entre eles. A potência deste encontro é resultante das trocas empreendidas relacionalmente e favorece a busca efetiva de soluções para a manutenção da vida.

A necessidade de ampliação da capacidade de escuta, na própria clínica, disponibilizando um sentido humanizado do atendimento, acolhendo os sofrimentos individuais, traduzindo-os em dimensões físicas, psíquicas e sociais tornam possíveis as ações/intervenções integradoras de todas estas dimensões ${ }^{(5-6)}$.

A clínica se expressa no cuidado ou na resposta ao sofrimento e às incertezas advindas de processos que impõem limites à capacidade de andar pela vida. A concepção da clínica seria a perspectiva de uma ação contextualizada socialmente e instrumentalizada de um conjunto de técnicas e ferramentas (homogêneas e homogeneizantes) a procurar respostas singulares para as necessidades e as demandas na saúde das pessoas ${ }^{(7)}$.

Nesse paradoxo muitas vezes a alternativa terapêutica oportunizada pelos serviços de saúde mental aos seus usuários limita-se à terapia medicamentosa e à internação esporádica. Este também comumente se apresenta fragmentado e departamentalizado em cada núcleo profissional específico, favorecendo a dissociação mais intensa ainda do sujeito em sofrimento ${ }^{(8)}$.

A complexa rede de relações envolvidas na produção do cuidado no espaço do CAPS, transversalisadas pela prática clínica, insere saberes e práticas, necessidades e demandas, condições e possibilidades no desafio de construir um cenário ativo para a efetivação das ações de saúde mental no campo psicossocial.

Nesse sentido, a partir de vivências acadêmicas, assistenciais e investigativas incorporadas ao universo subjetivo e sócio-motivacional dos autores, assim como, pela relevância da temática apresentada, o objeto deste estudo é a análise da produção do cuidado em saúde mental, tomando como recorte a prática clínica operada pelos trabalhadores do CAPS na produção do cuidado integral decorrente do estabelecimento de relações entre os sujeitos sociais envolvidos no processo.

Desse modo, objetiva-se analisar a prática clínica operada pelos trabalhadores de saúde mental no cotidiano do CAPS.

\section{METODOLOGIA}

A metodologia da pesquisa qualitativa, dentro de uma perspectiva crítica-analítica, foi escolhida como possibilidade de analisar o fenômeno social e suas relações no campo da saúde mental. Ainda é possível por meio desta opção dimensionar a compreensão dos significados, dos sentidos, das intencionalidades e das 
questões subjetivas inerentes aos atos, às atitudes, às relações e às estruturas sociais ${ }^{(9)}$.

A pesquisa foi realizada no município de Fortaleza-CE, no primeiro semestre de 2008. A capital do Estado do Ceará apresenta como diretriz da política municipal de saúde mental a concepção da atenção para com os sujeitos em sofrimento psíquico e a sociedade. Neste campo, também, como um direito do cidadão propiciando o suprimento de necessidades e proteção social.

A Rede Assistencial de Saúde Mental-RASM, de Fortaleza está sendo construída com serviços públicos de saúde mental substitutivos ao hospital psiquiátrico, interligados aos demais serviços públicos de saúde, e a equipamentos, dispositivos e recursos existentes na própria comunidade ${ }^{(10)}$.

A equipe de saúde mental a compor a escolha dos sujeitos participantes foi selecionada no âmbito da área geográfica da Secretaria Executiva Regional-SER IV, de acordo com a divisão geo-sanitária e políticoadministrativa do município de Fortaleza-CE.

Os sujeitos do estudo foram definidos na composição operacional da equipe de trabalhadores de saúde mental no CAPS sob investigação. O termo trabalhador de saúde expande o núcleo profissional restrito à formação técnica ou acadêmica e inclui outros participantes do processo de produção do cuidar. Foram escolhidos 14 sujeitos que, para ser descritos nos discursos, são apresentados por dois grupos: I (sete trabalhadores de nível de escolaridade básica) e II (sete trabalhadores de nível superior).

A amostragem intencional foi definida pela saturação teórica que, ao estabelecer ou fechar o tamanho final de uma amostra em estudo, interrompe a captação de novos componentes a partir da redundância e convergência de sentido e significado obtido na coleta e análise dos dados ${ }^{(11)}$.

Para a coleta de dados foram utilizadas duas técnicas: a entrevista semi-estruturada e a observação sistemática da prática clínica em saúde mental no contexto do CAPS. O estudo foi submetido à análise do Comitê de Ética em Pesquisa da Universidade Estadual do Ceará-UECE sob o processo $\mathrm{n}^{\circ}$. 074990026-8, adequando-se às normas da pesquisa envolvendo seres humanos evidenciada na livre e esclarecida participação, sendo livre para o direito de recusar tal participação ou retirar seu consentimento em qualquer fase da pesquisa, mantendo também sob sigilo total, as identidades por tempo indeterminado ${ }^{(12)}$.

A análise do material empírico, para o melhor entendimento do objeto de estudo, baseou-se na hermenêutica crítica em que o fundamento de análise é a práxis social na perspectiva crítico-analítica. Os passos operacionais foram: ordenação dos dados; classificação dos dados; e por fim, a análise final dos dados $^{(9)}$. Nessa etapa houve a possibilidade da fusão entre o real vivenciado pelos sujeitos sociais da pesquisa em seu cotidiano e em seus contextos práticos, e o mundo conceitual, teórico e também vivo do pesquisador, ambos com suas condições sóciohistóricas e culturais.

O processo de investigação no campo social e humano é produzido e produz, ao mesmo tempo, uma objetivação da realidade, assim como a objetivação do investigador que se torna também produto de sua própria produção ${ }^{(9)}$.

As categorias empíricas consistiram no eixo norteador da interface de análise entre os discursos confrontados e as situações vivenciadas e observadas pelos pesquisadores. Os resultados se apresentam, em seguida, na configuração analítica do objeto de estudo, dispostos em discurso e observações identificadas que se conformam na "Compreensão da prática clínica em saúde mental no cotidiano do CAPS”.

\section{RESULTADOS E DISCUSSÃO}

A análise da prática clínica dos trabalhadores de saúde mental ao realizar a produção do ato de cuidar consolidou a observação de que, muitas vezes, algumas abordagens se distinguem pela adequação imediata ao objeto de intervenção, no caso, o sujeito em sofrimento psíquico, e, assim, tornam-se prevalentes na vida cotidiana do CAPS.

O sentido terapêutico de cada abordagem adotada e exercida pelos trabalhadores de saúde mental na relação com o usuário, efetiva-se na manutenção do estado de equilíbrio da condição de saúde e na adaptação subjetiva às formas de convívio com o adoecer psíquico.

As abordagens terapêuticas grupais fortalecem também as relações entre os membros da equipe e os usuários participantes. A utilização desta prática no projeto terapêutico dos espaços de cuidado em saúde mental, principalmente no CAPS, parece compor a realidade cotidiana:

Os grupos terapêuticos ocorrem em todos os núcleos do CAPS e as temáticas são definidas dentro do projeto terapêtico específico dos 
participantes de cada grupo. As técnicas utilizadas são bastante interessantes e tomam como sentido básico a utilização de recursos simples e de fácil adesão pelos usuários, tais como: jornais, revistas, argila, cola, papel, cartolina, material reciclável, etc. A equipe demonstra habilidade terapêutica na condução dos mesmos e os problemas enfrentados apresentam uma resolutividade ampla e diversa, pois é percebido o compromisso com o encaminhamento de resoluções em todas as complexidades apresentadas. Muito embora, a limitação persista em alguns casos em que fica difícil a articulação intersetorial. Assim, a equipe busca sempre a troca das experiências e desafios nas reuniões semanais com todos os trabalhadores (Observação).

No cotidiano do CAPS, os grupos terapêuticos são instrumentos que possuem um amplo espectro de possibilidades para a atuação clínica da equipe de saúde mental. As temáticas necessárias para evidenciação e expressão da subjetividade humana são incorporadas de forma significativa nas intervenções propostas e pactuadas com o usuário.

Assim, ocorre o compartilhamento de experiências e vivências que se permite a partir da ocorrência de diálogos e encontros permeados pela escuta e pela orientação ativa na construção de projetos terapêuticos condizentes com as necessidades dos sujeitos envolvidos. A prática terapêutica grupal pode favorecer uma maior capacidade resolutiva por possuir vários olhares direcionados para um problema em comum $^{(13)}$.

O desenvolvimento da atividade grupal como recurso terapêutico apresenta-se como uma possibilidade de escolha entre a equipe do CAPS e os usuários. O andamento terapêutico proporcionado pelas trocas e intervenções, na busca pela melhor adaptação de vida, define qual mecanismo será adequado a esta prática. No entanto, os serviços que têm por objetivo a transformação das instituições segregatórias, iatrogênicas e eliminatórias do ponto de vista terapêutico devem priorizar a cidadania do sujeito em sofrimento psíquico acima da psicopatologia enraizada na lógica assistencial, neste caso, os CAPS precisam instituir dispositivos coletivos democráticos e, ainda, terapêuticos ${ }^{(14)}$.

Em conformidade com a política de saúde mental brasileira que apresenta como uma de suas diretrizes a ampliação dos serviços extra-hospitalares, no caso o CAPS, como estratégia para substituir a lógica hospitalocêntrica da assistência psiquiátrica, delineia-se a estruturação de um rede de cuidados em saúde mental ${ }^{(15)}$.

Consoante, na conjuntura brasileira, cresce a demanda por problemas de natureza psicossocial, expressos como ansiedade, depressão, angústia, medos, dores, entre outros. Os agravos psicossociais por um lado, e os limites do modelo médico-hegemônico em lidar com estes, por outro lado, apontam para a necessidade de se reorganizar as práticas de saúde ofertadas pelos serviços de saúde, reavaliando as relações entre a oferta e a demanda desses serviços ${ }^{(16)}$.

No CAPS, os discursos apresentados expressam um elemento necessário para a diferença da prática clínica na atenção psicossocial: a escuta. $\mathrm{Na}$ aplicação desta ferramenta está fortalecido o processo de mudança em que a assistência em saúde mental se encontra.

O serviço [CAPS] substitui o hospital psiquiátrico a partir do momento em que escuta mais o paciente (Grupo II).

Os trabalhadores do CAPS explicitam em todas as reuniões e atendimentos o compromisso para a inversão da lógica manicomial, asilar e excludente. Tal fato é observado nas condutas empreendidas, na participação em atividades de promoção da saúde mental e também nas reuniões associativas e representativas da área da saúde mental (Observação).

Por serem considerados comunitários, os CAPS inserem-se em determinada cultura, em território definido, com seus problemas e suas potencialidades, arena na qual as "crises" devem ser enfrentadas, resultados que são, geralmente, de fatores do indivíduo, de sua família, eventualmente de seu trabalho e seguramente de seu meio social ${ }^{(17)}$.

Em relação à condução terapêutica grupal, esta permite e deve estimular a integração da própria equipe no desenvolvimento das atividades junto aos usuários. Portanto, se é possível incluir dentro do projeto contratual de discussão temática os diversos campos envolvidos na manutenção da saúde mental, este devir pode ser possibilitado pela inserção de membros da equipe que podem contribuir com a diversificação da clínica.

No processar do trabalho e da relação que se estabelece entre serviço e usuário, operam processos 
tecnológicos - trabalho vivo em ato - que visam à constituição de relações de escutas, de vínculos e de compromissos em projetos de intervenção, os quais atuem sobre a demanda (problemas/necessidades) em saúde, tendo como finalidade o controle do sofrimento e da produção da saúde ${ }^{(18)}$.

A utilização das tecnologias relacionais interfere consubstancialmente na efetiva produção do cuidado. Para tanto, exige-se o compromisso de se utilizar o conteúdo das relações como substrato da tecnologia empreendida, o que irá ressignificar o cotidiano, reconstruindo intersubjetividades e, suprindo necessidades de saúde na concretização do cuidado ${ }^{(19)}$.

A habilidade do terapeuta para com o seu grupo está também em perceber as necessidades dos usuários em relação a dúvidas e anseios que possam ser enfrentados ou compartilhados por outros sujeitos externos ao grupo, mas comprometidos com o cuidado integral dos mesmos.

Mas agora eu estou pedindo que eles façam grupo [...]. Não é um grupo a mais [...] mas que eles possam visitar os grupos existentes para tirar as dúvidas que eles têm sobre medicação [...] (Grupo II).

Na lida cotidiana do CAPS, converge a necessidade da implementação de práticas que se transversalizem nos diversos campos de saberes e que estejam voltadas para os contextos sociais da realidade comunitária em que os usuários mantêm suas relações e emergem suas necessidades. A inclusão de temáticas e a evocação de situações vividas no grupo terapêutico com o suporte de diversos atores, trabalhadores de saúde ou não, é o caminho para a resolução de problemas.

Assim, os trabalhadores de saúde mental caracterizam a transversalidade da clínica ao expor que ela possibilita conexões, extensões e articulações como patamar comum das práticas: a clínica comporta um coeficiente de transversalidade mais acentuado que a prática clássica, e os atravessamentos podem ser tomados como elementos dinamizadores de novas ações que estendem o alcance da clínica ao portador de sofrimento mental ${ }^{(20)}$.

Nesse sentido, a criatividade torna-se um elemento também essencial para o desenvolvimento das atividades grupais. $\mathrm{O}$ aspecto lúdico envolve os sujeitos de forma alegre e emocional na terapia empreendida. No entanto, a criatividade pode se relacionar também com as dificuldades de insumos ou materiais e na utilização alternativa de outros.
[Temos] grupos de mulheres, grupos de bordado, [vários] grupos [...] e [vamos] discutindo e vendo como é que se trabalha. Se tiver [material] trabalha-se com o que tem; se não tem, [a gente] cria (Grupo II).

As abordagens terapêuticas grupais empreendidas no CAPS pela equipe multidisciplinar são constituídas de especificidades operacionais e conceituais que se apresentam nos tipos de terapias encontradas em cada situação em que o cuidado é efetivado.

Na diversidade das práticas, observam-se as singularidades, identificadas a partir de recursos internos e sociais, ao procurar de forma compartilhada o sentido em sua situação e para o seu projeto de vida, a fim de promover sua saúde, qualidade de vida e autonomia ${ }^{(21)}$.

Uma prática exercida na clínica psicossocial é a arte-terapia que apresenta-se como recurso terapêutico no tratamento compartilhado entre os sujeitos, já que incorpora a diversificação de situações e transtornos psíquicos e desta forma, favorece a heterogeneidade dos grupos.

O relaxamento também permeia as atividades da arte-terapia, na medida em que a tensão, outrora incorporada pela mente, agora se transpõe para as atividades operadas junto a materiais por meio da técnica artística.

[No CAPS] tem a arte terapia. Ajuda no tratamento do paciente [...] ajuda muito. Na arte terapia [...] eu trabalho com o ensino da dança, o chão de dança, chão de expressividade corporal (Grupo I).

O grupo terapêutico de arte terapia [...] nós fazemos heterogêneo. [...] não é separado por transtornos. [Na] arte terapia [trabalha-se] o relaxamento[...]. [O arteterapeuta do CAPS] é uma pessoa muito capacitada com esta questão (Grupo II).

Na diversidade clínica, temos a expressão corporal e o próprio condicionamento físico como práticas operadas juntamente com os usuários do CAPS nas sessões de terapia corporal. A inclusão da arte e da expressão artística proporciona um significado a mais para a mobilização corporal dos participantes deste tipo de grupo.

O enfoque se dá na condição física dos usuários do CAPS, principalmente dos egressos de internações sucessivas, por se encontrarem comumente debilitados devido ao uso constante de medicação, e à consequente 
evidenciação dos efeitos colaterais relacionados à mobilidade muscular.

A contratura muscular e a perda sucessiva da habilidade cognitiva e motora, por vezes, limitam o usuário na realização de seus afazeres mais simples e comuns, como cuidar da higiene e da aparência ou até mesmo na locomoção independente.

[...] agora a gente tá realizando o condicionamento funcional que é uma atividade física [...] e o público é exatamente essas pessoas [que] pode ser qualquer pessoa que esteja aqui [...] que tenha vontade de fazer alguma atividade física [...] envolvendo atividades que a terapeuta ocupacional faz. Geralmente com os psicóticos ou [com aqueles] que fazem uso de medicação muito tempo e já tem alguma rigidez. Tem dificuldade de se levantar ou então não está trabalhando. Esse cuidado [está] envolvendo o físico dele mesmo. Por exemplo, o bambolê [...] o movimento de se vestir [...] de pentear o cabelo [ ...] algumas atividades nesse sentido (Grupo II).

Os trabalhos terapêuticos que envolvem o corpo auxiliam os pacientes a se tornarem conscientes das verdadeiras relações que há entre corpo, mente e emoção. O desenvolvimento das atividades com a evidência dos sentimentos e o estímulo musical proporciona o contato e a harmonia da percepção do paciente sobre o processo de adaptação e recuperação ${ }^{(22)}$.

A massoterapia também está presente nas atividades da equipe do CAPS de forma transversal na medida em que os usuários de diferentes grupos e condições de saúde aderem a este procedimento. Por meio da massoterapia é possível acompanhar as dificuldades, necessidades e sintomas subjetivos e, por vezes, crônicos dos usuários.

Eu faço [...] massoterapia [no CAPS]. Eu faço a massagem nos pacientes. [...] ela transforma o que ela gostaria de falar na respiração [...]. [Eu peço] que ela fique só pensando em coisas boas. [...] pensar em coisas boas. [...]. O momento é dela, então a gente não deve também ficar conversando com ela [...] a massagem demora mais ou menos uns quarenta minutos porque a gente trabalha o corpo todo, do fio do cabelo à ponta dos pés (Grupo I).

A realização da massoterapia no CAPS ocorre de forma efetiva com agendamento e compromisso da terapeuta e dos usuários na atividade terapêutica. É percebida a satisfação de ambos no processo terapêutico realizado (Observação).

A inserção da família nas práticas grupais também se faz necessária para um melhor convívio com o parente em sofrimento psíquico e também como mecanismo de expressão e compartilhamento dos sentimentos e emoções vivenciados no cotidiano do lar.

[No CAPS] tem grupo que é relacionado à família [...] quando os familiares estão de acordo [em participar] porque também a família sofre muito com os pacientes e com os transtornos dele (Grupo II).

A importância da inserção familiar no contexto do CAPS conforma-se pela singularidade da dinâmica cuidadora, em que as relações se apóiam na desconstrução da idéia limitada de atuar somente no sofrimento psíquico, mas também na integração, acolhimento, cuidado e inclusão dos atores dessa relação nos espaços cotidianos da vida: trabalho, lazer, moradia, entre outros ${ }^{(13)}$.

As abordagens terapêuticas operadas no CAPS, embora expressivamente contextualizadas nos grupos terapêuticos, incorporam também outras atividades e formas de lidar com a assistência ao transtorno psíquico e na promoção da saúde mental no território.

Os serviços ofertados no CAPS apresentam várias possibilidades de acesso ao serviço de saúde mental e incorporam saberes e práticas balizadas pela necessidade de cada usuário.

[No CAPS] tem a psicologia [...], tem a terapia ocupacional [...] tem grupo de sonhos, [...] de mulheres, [...] da maior idade, [...] de redução de danos, [...] de leitura, [...] da medicação [neste] a gente orienta. [Dentre as] atividades que o CAPS realiza tem terapia ocupacional, tem grupo de leitura, tem o grupo de artesanato, tem vários grupos aqui (Grupo I).

[Aqui no CAPS, os usuários] fazem marcenaria, tem grupo de mulheres que mexem com sabonete [...] é muito bom também (Grupo II).

O projeto terapêutico do CAPS deve conduzir todos os recursos disponíveis para o cuidado em sua linha de atuação de forma singular para cada usuário 
e sua necessidade. As intervenções clínicas compartilhadas estruturam uma cadeia de produção do cuidado de forma integral ${ }^{(23)}$.

A atuação do CAPS no território é uma das premissas da atenção psicossocial, por considerar ser este o espaço mais próximo do viver de cada usuário atendido. No bairro ou na comunidade é onde se encontram os elementos da convivência social tais como vizinhos, amigos e familiares.

O trabalho em saúde mental continua a delinear o acontecer histórico, pois interpõe a potência da transformação dos ambientes, das naturezas e das subjetividades singulares e coletivas. Os dispositivos estratégicos são definidos no agir, no exercício prático e na confluência de experiências, possibilidades e desafios a serem conquistados.

A visita domiciliar é uma prática desenvolvida pela equipe do CAPS no sentido de se aproximar da realidade social do usuário no enfrentamento de suas vulnerabilidades. Ainda, têm-se a promoção da saúde que permeia as atividades desenvolvidas no CAPS por meio da educação em saúde voltada para a discussão sobre os temas relacionados à higiene corporal, alimentação, redução de danos em práticas de risco, dentre outros.

O compartilhamento de saberes assimila a lógica do apoio e da força propulsora por meio de iniciativas como visitas domiciliares no território, apoio matricial em saúde mental, discussão e construção do conhecimento, enfim, nas atividades parcializadas em rede, em jogo, em relação de serviços, com sujeitos e, principalmente, em ações.

A multidisciplinaridade se faz presente no cotidiano do CAPS, já que cada núcleo de saber profissional atua de modo a operar suas ferramentas e instrumentos de forma integrada e específica para compor o cuidado em saúde mental.

Em outra atividade, na abordagem individual, tem-se o atendimento dispensado ao usuário do CAPS por meio do suporte psico-emocional, também à própria equipe; a dispensação dos medicamentos e/ou insumos inerentes à terapêutica; dentre outros exemplos de serviços ofertados.

[No CAPS] tem os atendimentos médicos [...] os atendimentos individuais [...] da psicologia, a terapia ocupacional. [A] TO está implantando os grupos junto com um profissional de referência da unidade [PSF] e fazendo essa ponte lá. As atividades da farmácia são o gerenciamento, a dispensação, a organização e o cadastro e também a orientação. Nós temos muita coisa prá fazer. $E$ com o terceiro farmacêutico a gente vai ter tempo para fazer um grupo que a gente ainda vai organizar (Grupo II).

Independente da forma de abordar terapeuticamente seja na relação individual ou grupal, a clínica deve conceber o sujeito em sofrimento com sua singularidade e subjetividade. A definição do planejamento terapêutico é múltiplo e dinâmico, podendo ser adaptado e implementado dentro do próprio processo e tempo.

Para tanto, é fundamental que os trabalhadores disponham de formação permanente, no sentido de permitir a auto-realização, tanto no plano pessoal quanto profissional do trabalho psicossocial. A atuação multidisciplinar em saúde mental propicia a necessidade também da interdisciplinaridade no agir em saúde, ao articular práticas e saberes diferentes na promoção da assistência integral ${ }^{(24)}$.

$\mathrm{O}$ trabalho em equipe é fortalecido no CAPS no momento em que a atuação requisita ações de dimensão interdisciplinar, em que os limites de cada saber se interseccionam na busca da melhor atitude junto a quem precisa.

Na equipe interdisciplinar do CAPS todos dão o seu ponto de vista e todos dão sua contribuição nesse processo, então esse processo existe. Se isso se perder não existe mais CAPS. A finalidade do CAPS é isso [...] é a equipe interdisciplinar e a troca de idéias de todos [...] até mesmo a menina da cozinha, o que varre, o que limpa o colchonete [...] tem uma interação muito importante por aqui (Grupo I).

Eu acho que agora o CAPS cresceu muito com relação a isso. A equipe tá mais interdisciplinar. Tão sendo mais interdisciplinar, ainda mais na questão clínica, esse olhar [...] está jóia (Grupo II).

Portanto, a meta do trabalho em equipe do CAPS não deve seguir apenas a uma homogeneização dos saberes técnicos dos diferentes trabalhos profissionais, mas enfrentar as possíveis desigualdades e diferenças no processo cotidiano de trabalhar/cuidar ${ }^{(25)}$.

Embora a magnitude do trabalho em equipe desenvolvido no CAPS, através de práticas predominantemente grupais, esteja contextualizada nos 
discursos anteriores, apresentam-se ainda algumas situações que divergem do apresentado.

É uma pena, mas infelizmente, a prática do CAPS hoje, se pudesse facilitar não deixava o paciente sem medicação (Grupo I).

Em alguns momentos, foi presenciada a requisição direta por parte de familiares e acompanhantes pela consulta com o psiquiatra, pois somente ele poderia prescrever o remédio necessário. Em algumas vezes, foi escutado a expressão: ah, hoje só tem grupo (Observação).

Os discursos apresentam uma divergência da prática do CAPS anteriormente discutida, em que a prescrição da medicação ainda apresenta-se como um recurso terapêutico pelo fato de inibir o surgimento das crises, o que normalmente acarreta as internações em leitos psiquiátricos. A tensão de quem atende no CAPS recorre a este pensar por vivenciar, muitas vezes, que a condição de atendimento para este tipo de procedimento acaba por ter uma demanda grande e o acesso dificultado.

Diferentemente da intervenção pontual e limitada da medicação com recurso único, para efetivação da ampliação e diversificação pretendida para a prática clínica incorporando elementos da subjetividade, como a escuta e o diálogo, o CAPS precisa operacionalizar dentro de sua capacidade e de acordo com os recursos disponibilizados. O tempo parece ser uma prerrogativa essencial para a consolidação das técnicas relacionais para com o usuário.

Não dá tempo [...]. [No CAPS temos] os serviços, os grupos, tem a consulta, mais o que eu noto é que tinha que ter mais profissionais em todas as categorias já que é bem grande a demanda. Eu acho que prá você dar um serviço de qualidade, você tem que ter tempo. Pois é muito difícil o médico atender só vinte pacientes [por período] (Grupo II).

No entanto, o engajamento direto dos trabalhadores de saúde, na prática clínica grupal, depende também da forma como é constituída a distribuição dos atos laborais na equipe multiprofissional do CAPS já que alguns componentes da equipe estão diretamente ligados a atividades relacionais de natureza mais individual entre quem cuida e é cuidado.

As novas dimensões práticas clínicas surgidas na saúde mental, a partir do encontro das políticas públicas com o cotidiano local, mesmo que ainda misturadas com elementos do modelo clássico e hegemônico da lógica biomédica, levam os sujeitos, cada vez mais, a lidarem com esse entrecruzamento. Em todas as formas disposta, sempre, como um atravessamento dificultador ou possibilitador da clínica desenvolvida ${ }^{(20)}$.

No processo de enfrentamento das adversidades e formulações terapêuticas, as situações psicossociais requisitam a formação e construção de uma rede de apoio, em que a integralidade dos serviços e a intersetorialidade seja uma fundamentação precípua.

Estamos [equipe] vivendo esse processo de sair daqui [dentro do CAPS] para fortalecer essa rede. Porque se isso não acontece aqui vira um hospital [...] precisamos criar espaços sociais para que se absorvam essas pessoas porque se não? [...] mas não é fácil assim (Grupo II).

A conjuntura brasileira apresenta como característica social a desigualdade. Embora os mecanismos de aumento da produção se efetivem em alguns setores da economia, não conseguem interpor as devidas medidas de distribuição justa e equânime do que é produzido. O resultado final desta situação é o aumento da pobreza e da miséria logicamente inserida também no contexto do CAPS:

Muitos que lancham aqui à tarde, no dia seguinte chegam a dizer que tá apenas com aquele lanche do dia anterior (Grupo I).

Na hora marcada para a dispensação da alimentação, é visível, a necessidade do usuário pelo lanche e o almoço servido pela funcionária da cozinha (Observação).

Pode-se pensar, nesse contexto da realidade brasileira, sobre os mecanismos de exclusão social, haja vista a malha centrífuga a que atam os desiguais, desinteressantes, desprovidos, arruinados e desfavorecidos. O mote de contraposição, o da inclusão, é premente e articula-se ao discurso da política econômica no eterno jogo entre o público, o privado e o não-governamental. A inclusão tangenciada pela prática terapêutica comunitária abrange as lacunas da conjuntura da miséria, ou permite maior percepção para também agir sobre e contra elas. 
Cabe, então, para se delinear uma cartografia da clínica no CAPS, por seu elaborar dialético, a abordagem construtiva e constante sobre o(s) significado(s) desta prática. O cuidado enseja posições, entrecruzamentos, ideários, saberes e valores, indo além da apologia intervencionista, do olhar clínico ditador e detentor de uma verdade, mas que se estabelece ontologicamente em reconfigurações e reconstruções a cada nova possibilidade que se abre para cuidar, para ver e para tanger a realidade vivida.

\section{CONSIDERAÇÕES FINAIS}

As ações desenvolvidas se adequam ao esperado e previsto no cotidiano da equipe do CAPS. $\mathrm{O}$ esforço pactuado em efetivar abordagens mais subjetivas está presente em todos os momentos da assistência. O grupo terapêutico permeia todas as iniciativas de intervir, de assistir, de cuidar. Deste modo, desfaz-se, neste espaço, a concepção de utilizar o mesmo como mecanismo de atendimento em massa ou espaço para imposição de saberes.

Por conseguinte, o grupo é a ferramenta operativa escolhida pela equipe do CAPS tanto para desenvolver o trabalho assistencial em saúde mental como também para promover o encontro de subjetividades da própria equipe.

Na conduta grupal, as tensões se flexibilizam na conversa direta, compartilhada e equânime entre os trabalhadores. As atividades de roda de conversa intensificam o papel das tecnologias das relações no próprio processo de trabalho em saúde mental.

A elaboração da rede de cuidados em saúde mental deve ter como base a prática clínica operada pelas equipes dos CAPS. São nestes espaços em que se percebem as verdadeiras e variadas formas de intervenção terapêutica, as deficiências operacionais, as demandas prevalentes e a resolutividade real. A imposição de determinações políticas operacionais sobre a dinâmica do cuidado apenas desconfigura o processo dialético de (re)construção da assistência.

O cotidiano se faz no presente e o dia seguinte já insere suas transformações inócuas de um trabalho feito ou desfeito. A formulação de políticas públicas e efetivas deve perceber as singularidades do espaço vivo de tais práticas. Desse modo, a atenção psicossocial em suas dimensões, emana a necessidade da ação intersetorial.

O CAPS precisa incorporar e atuar no seu papel de agenciador e ordenador das ações de saúde mental no território. A prática clínica é extra-hospitalar, mas também é extra-consultório, extra-sala de recepção. O território mantém suas estruturas e coberturas de atenção que, embora diferentes, também incidem na melhoria de vida do usuário, no nosso caso, do SUS.

\section{REFERÊNCIAS}

1. Amarante P. Novos sujeitos, novos direitos: o debate em torno da reforma psiquiátrica. Cad Saúde Publ. 1995 11(3):491-4.

2. Campos RO. A promoção à saúde e a clínica: o dilema “promocionista”. In: Castro A, Malo M, organizadores. SUS: ressignificando a promoção da saúde. São Paulo: Hucitec/ OPAS; 2006. p. 62-74.

3. Amarante P. Saúde mental e atenção psicossocial. Rio de Janeiro: Fiocruz; 2007.

4. Campos GWS, Amaral MA. A clínica ampliada e compartilhada, a gestão democrática e redes de atenção como referenciais teóricos-operacionais para a reforma do hospital. Cienc Saúde Col. 2007;12(4): 849-59.

5. Santos AM, Assis MMA. Da fragmentação à integralidade: construindo e (des)construindo a prática de saúde bucal no Programa de Saúde da Família (PSF) de Alagoinhas, BA. Cienc Saúde Col. 2006;11(1):53-61.

6. Campos GWS. Reforma da reforma: repensando a saúde. São Paulo: Hucitec; 1992.

7. Favoreto CAO. A velha e renovada clínica dirigida à produção de um cuidado integral em saúde.In: Pinheiro R, Mattos RA, organizadores. Cuidado: as fronteiras da integralidade. Rio de Janeiro: CEPESC/UERJ/ ABRASCO; 2006. p.205-19.

8. Campos RO. Clínica: a palavra negada - sobre as práticas clínicas nos serviços substitutivos de saúde mental. Saúde em Debate. 2001 Mai/Ago;25(58):98-111.

9. Minayo MCS. O desafio do conhecimento: pesquisa qualitativa em saúde. São Paulo: Hucitec; 2008.

10. Andrade LOM, Oliveira RFB, Bastos ENE, Fialho MB, Costa LD. Saúde mental e cidadania: a resposta de Fortaleza, Ceará. Divulgação em Saúde para Debate. 2007 Jun;(40):57-1.

11. Fontanella BJB, Ricas J, Turato ER. Amostragem por saturação em pesquisas qualitativas em saúde: contribuições teóricas. Cad Saúde Publ. 2008 Jan;24(1):17-27. 
12. Ministério da Saúde (BR). Conselho Nacional de Saúde. Diretrizes e normas regulamentadoras de pesquisa envolvendo seres humanos. Resolução n.196, 10 de outubro de 1996. Brasília; 1996.

13. Schrank G, Olschowsky A. O centro de atenção psicossocial e as estratégias para inserção da família. Rev Esc Enferm USP. 2008;42(1):127-34.

14. Lancetti A, organizador. Saúde loucura n. 4: grupos e coletivos. São Paulo: Hucitec; 1994. Clínica grupal com psicóticos: a grupalidade que os especialistas não entendem; p. 155-72.

15. Ministério da Saúde (BR). Secretaria de Atenção à Saúde. Departamento de Ações Programáticas Estratégicas. Departamento de Atenção Básica. Coordenação Geral de Saúde Mental. Coordenação de Gestão da Atenção Básica. Saúde Mental e a Atenção Básica: o vínculo e o diálogo necessários. Brasília: MS; 2003.

16. Lacerda A, Valla VV. Um outro olhar sobre a construção social da demanda a partir da dádiva e das práticas de saúde. In: Pinheiro R, Mattos RA, organizadores. Construção social da demanda: direito à saúde, trabalho em equipe, participação e espaços públicos. Rio de Janeiro: CEPESC/UERJ: ABRASCO; 2005. p. 279-291.

17. Alves DS. Integralidade nas políticas e saúde mental.In: Pinheiro R, Mattos RA, organizadores. Os sentidos da integralidade na atenção e no cuidado à saúde. Rio de Janeiro: IMS- UERJ/ABRASCO; 2006. p. 169-78.

18. Franco TB, Bueno WS, Merhy EE. O acolhimento e os processos de trabalho em saúde: Betim, Minas Gerais, Brasil. Cad Saúde Publ. 1999;2(15):345-53.

19. Rossi FR, Lima MADS. Acolhimento: tecnologia leve nos processos gerenciais do enfermeiro. Rev Bras Enferm. 2005;58(3):305-10.

20. Ferreira Neto JL. Práticas transversalizadas da clínica em saúde mental. Psicol Reflex Crit. 2008;21(1):111-8.

21. Zoboli E. Cuidado: práxis responsável de uma cidadania moral. In: Pinheiro R, Mattos RA, organizadores. Razões públicas para a integralidade em saúde: o cuidado como valor. Rio de Janeiro: IMS/ UERJ/CEPESC/ABRASCO; 2007.p. 63-78.

22. Peto AC. Terapia através da dança com laringectomizados: relato de experiência. Rev LatinoAm Enferm. 2000 Dez;(8)6: 35-9.

23. Franco TB, Magalhães JrHM. Integralidade na
Assistência à saúde: a organização das linhas de cuidado. In: Merhy EE. et al., organizadores. O trabalho em saúde: olhando e experienciando o SUS no cotidiano. São Paulo: Hucitec; 2006. p. 125-33.

24. Jorge MSB, Randemark NFR, Queiroz MVO, Ruiz EM. Reabilitação Psicossocial: visão da equipe de Saúde Mental. Rev Bras Enferm. 2006;59(6):734-9.

25. Milhomem MAGC, Oliveira AGB. O trabalho em equipe nos centro de atenção psicossocial-CAPS. Cogitare Enferm. 2007 Jan/Mar;12(1):101-8. 